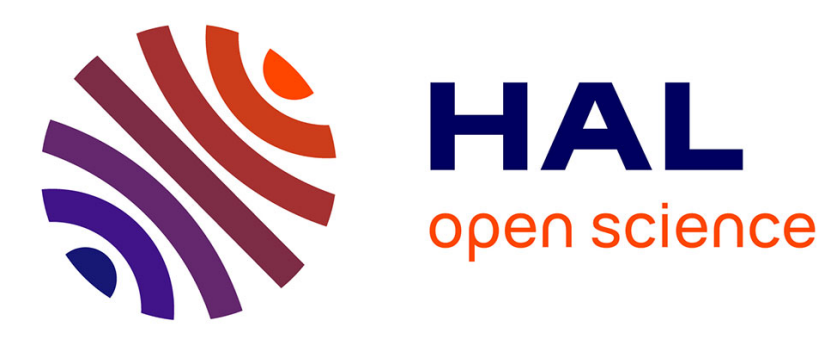

\title{
High-Frequency-Induced Cathodic Breakdown during Plasma Electrolytic Oxidation
}

Alexandre Nomine, Anna V. Nominé, N. St.j. Braithwaite, T. Belmonte, G. Henrion

\section{- To cite this version:}

Alexandre Nomine, Anna V. Nominé, N. St.j. Braithwaite, T. Belmonte, G. Henrion. HighFrequency-Induced Cathodic Breakdown during Plasma Electrolytic Oxidation. Physical Review Applied, 2017, 8 (3), 10.1103/PhysRevApplied.8.031001 . hal-02106024

\section{HAL Id: hal-02106024 \\ https://hal.univ-lorraine.fr/hal-02106024}

Submitted on 22 Apr 2019

HAL is a multi-disciplinary open access archive for the deposit and dissemination of scientific research documents, whether they are published or not. The documents may come from teaching and research institutions in France or abroad, or from public or private research centers.
L'archive ouverte pluridisciplinaire HAL, est destinée au dépôt et à la diffusion de documents scientifiques de niveau recherche, publiés ou non, émanant des établissements d'enseignement et de recherche français ou étrangers, des laboratoires publics ou privés. 


\title{
High-Frequency-Induced Cathodic Breakdown during Plasma Electrolytic Oxidation
}

\author{
A. Nominé, ${ }^{1,2, *}$ A. V. Nominé, ${ }^{1,2}$ N. St. J. Braithwaite, ${ }^{1}$ T. Belmonte, ${ }^{2}$ and G. Henrion ${ }^{2}$ \\ ${ }^{1}$ Department of Physical Sciences, Open University, \\ Walton Hall, Milton Keynes MK7 6AA, United Kingdom \\ ${ }^{2}$ Institut Jean Lamour, CNRS, Université de Lorraine, Parc de Saurupt, 54011 Nancy, France \\ (Received 10 May 2017; revised manuscript received 9 August 2017; published 12 September 2017)

\begin{abstract}
The present communication shows the possibility of observing microdischarges under cathodic polarization during plasma electrolytic oxidation at high frequency. Cathodic microdischarges can ignite beyond a threshold frequency found close to $2 \mathrm{kHz}$. The presence (respectively, absence) of an electrical double layer is put forward to explain how the applied voltage can be screened, which therefore prevents (respectively, promotes) the ignition of a discharge. Interestingly, in the conditions of the present study, the electrical double layer requires between 175 and $260 \mu$ s to form. This situates the expected threshold frequency between 1.92 and $2.86 \mathrm{kHz}$, which is in good agreement with the value obtained experimentally.
\end{abstract}

DOI: $10.1103 /$ PhysRevApplied.8.031001

Plasma electrolytic oxidation (PEO) is at a pivotal moment of its development. If this process has undeniable assets for surface treatments of light alloys (high growth rate, high ultimate coating thickness, ecofriendliness, wear, and corrosion resistance, etc.), the high energy consumption and the lack of understanding of the fundamental processes underlying the breakdown and the oxidation mechanisms still limit a larger scale development.

Improving the energetic efficiency of PEO is a major stake and several strategies can then be followed: dual treatments [1], addition of nanoparticles [2,3], electrolyte composition [4,5], and electric regimes [5-8]. Here, we focus on the influence of the electric regime as it has a direct and strong influence on both the space and time properties of microdischarges (MD), which affect the coating growth. Interestingly, the best properties and the highest growth rates of coatings are obtained while using a bipolar current waveform [5,9], even though MDs are only observed during the anodic (i.e., positive) half-period [10-12] in these conditions.

To explain this observation, one should keep in mind that the growth of PEO coatings relies on a balance between the constructive effect of MDs (oxidation and coating growth) and their destructive effect (large craters and porosities). Several studies conducted either by high-speed video imaging [5,6,11-18] or by direct electrical measurements $[10,19]$ have investigated this balance. They made it possible to correlate space and time parameters of MDs (number, lifetime, size) and the properties of as-grown coatings (thickness, porosity). In short, large and long-lived discharges promote the growth of high temperature phases but create large porosities (several tens of $\mu \mathrm{m}$ ), high roughness at limited growth rates (strong destructive effect

* Corresponding author. alexandre.nomine@univ-lorraine.fr of MDs). On the other hand, too small and short-lived MDs will create more homogeneous coating but with a lower amount of high-temperature phases and also at limited growth rates (weak constructive effect).

Nevertheless, all of these studies support the same conclusion: adjusting the cathodic half-period probably opens up the possibility to tune the behavior of anodic MDs. Then, combining high-growth rates, low levels of large-scale porosity (bigger than $10 \mu \mathrm{m}$ ) and a significant proportion of high-temperature phases becomes possible. Cathodic polarization is actually needed to prevent from the excessive charge accumulation on the coating surface, which is responsible for large discharges. In spite of an important energetic cost, this cathodic cleaning is an excellent way to control the PEO process. Nevertheless, a more efficient use of the cathodic half-period, possibly with the presence of cathodic discharges, might improve the process energetic efficiency and bring PEO closer to large scale production.

Since PEO has often been compared to anodizing, it has been admitted for a long time that PEO discharges could only be observed under anodic (i.e., positive) polarization. However, recent studies have shown the possibility to observe microdischarges under cathodic polarization, both on magnesium [20-23] and aluminum [23,24] substrates either by using uncommon compositions of electrolytes [20,21] or by applying high-current density (several $\mathrm{kA} \mathrm{dm}^{-2}$ ) [24]. A subsequent study in similar conditions to Ref. [20] has shown that cathodic discharges do not take part in the growth of an oxide coating and rather have a detrimental effect on it [22].

Conditions in which cathodic and anodic discharges in different substrate and electrolyte conditions have been set out by Nominé et al. [23] and an explanation based on the formation of an electrical double layer (EDL) has been proposed. Results of this study tend to show that an EDL may form on the surface of PEO coatings and generate a local electric field that can either screen or amplify the 
externally applied electric field. The result is to respectively prevent or promote breakdown at a given sample polarization. Similar results had been previously reported by Lukeś et al. [25] with a different plasma (corona discharge) generated in liquids.

PEO is a rather complex case of study involving the four states of matter interacting in a small volume (less than $1 \mathrm{~mm}^{3}$ ) during short time scales (from $\mu$ s to $\mathrm{ms}$ ) [26]. The majority of investigations have dealt with the study of microdischarges by means of high-speed video imaging [13] and optical emission spectroscopy [27-29] treat actually a large number of events $10^{5}$ per $\mathrm{dm}^{2}$ per second). To overcome this difficulty, the Gordon Laboratory has developed a setup that makes it possible to study one individual discharge at a time $[10,19,30]$ and to simultaneously record its current and image its shape [26,31].

The experimental procedure followed to isolate one discharge has been described in detail in previous works $[10,19,26,30]$, the PEO process being from Keronite ${ }^{\circledR}$ rig and operating from 50 to $2500 \mathrm{~Hz}$ with a current density of $30 \mathrm{~A} \mathrm{dm}^{-2}$. The idea is to connect a small wire, the smaller electrode, to a plate serving as a larger electrode. The small area of the wire helps to localize the discharge event, even though its triggering in time remains stochastic. Both larger and smaller electrodes are made of aluminum Al-6082 alloy. The electrolyte is a dilute aqueous solution of potassium hydroxide $\left(1 \mathrm{~g} \mathrm{~L}^{-1} ; 0.018 \mathrm{~mol} \mathrm{~L}^{-1}\right)$ and sodium silicate $\left(1.65 \mathrm{~g} \mathrm{~L}^{-1} ; 0.0135 \mathrm{~mol} \mathrm{~L}^{-1}\right)$. During the PEO treatment, an oscilloscope (Pico Technology, Picoscope 6403) measuring the voltage and the current delivered by the power supply as well as the current flowing through the smaller sample (see Fig. 1 in Ref. [19]) has been synchronized with an ultra-high-speed camera (Photron SA 1).

Figure 1 shows the time evolutions of voltage and current flowing through the smaller sample. Current peaks have been attributed to discharge events [32]. At lower frequency, MD appear in "cascade": several discharge events follow one after the other with durations ranging from tens to hundreds of $\mu \mathrm{s}$, offtimes being in the ms range (see Fig. 1 and Refs. [19,32]). This cascade effect logically disappears when the current half-period becomes close to the typical duration of a discharge, which is $1.5 \mathrm{kHz}$. In this case, we can see that one and only one discharge appears per cycle and that breakdown occurs only during the anodic half-period (see Fig. 1). At $2 \mathrm{kHz}$, we can clearly see that some anodic discharge events are shut down by the inception of the cathodic period. Moreover at 2 and $2.5 \mathrm{kHz}$ and after a certain amount of time (typically 15-20 min), intense current peaks
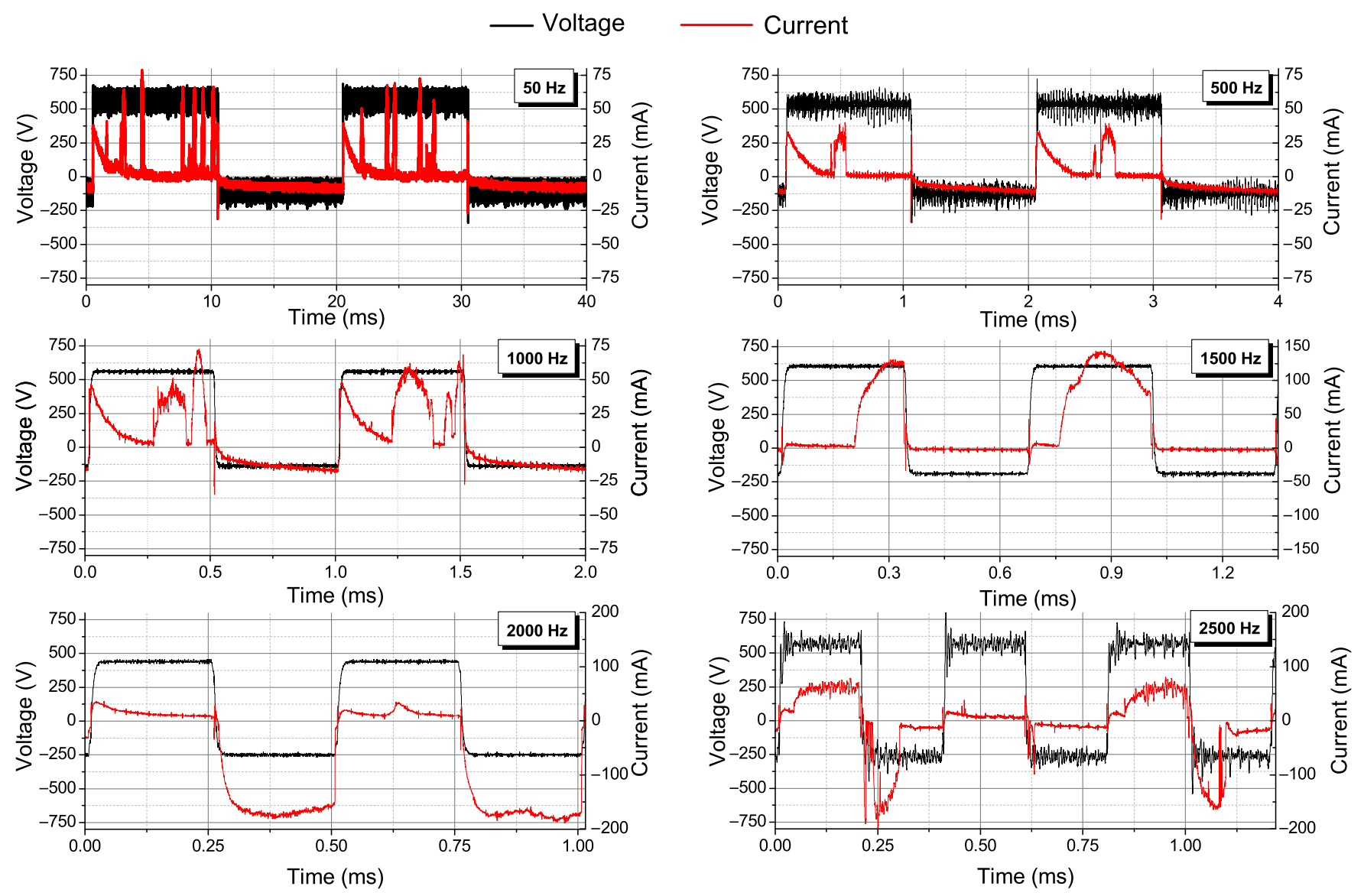

FIG. 1. Current and voltage time evolutions at different frequencies in the PEO process of the Al-6082 aluminum alloy in alkaline silicate electrolyte $\left([\mathrm{KOH}]=1 \mathrm{~g} \mathrm{~L}^{-1},\left[\mathrm{Na}_{2} \mathrm{SiO}_{3}\right]=1.65 \mathrm{~g} \mathrm{~L}^{-1}\right)$. 
are observed during the cathodic half-period, which suggests the presence of cathodic discharges. These cathodic current peaks remain until the end of the treatment $(30 \mathrm{~min})$.

This observation is confirmed by high-speed imaging (Fig. 2). Two different discharge spots, one during the anodic half-period and one during the cathodic half-period are clearly visible (see Fig. 2). It is worth noting that anodic and cathodic discharges occur at different locations on the sample. A priori, there is no rapid inversion of the charge motion that could maintain the plasma at the same location during the voltage reversal.

The presence of a cathodic discharge on an aluminum surface at a $p \mathrm{H}$ significantly higher than the isoelectric point may appear at first sight surprising and somehow contradictory with some published results [23]. On the other hand, the fact that the presence of cathodic discharges is triggered at a high frequency (above $2 \mathrm{kHz}$ - see Fig. 1) suggests that physical phenomena related to charge mobility are at stake. The velocity of charge carriers $v_{c}$ in a given
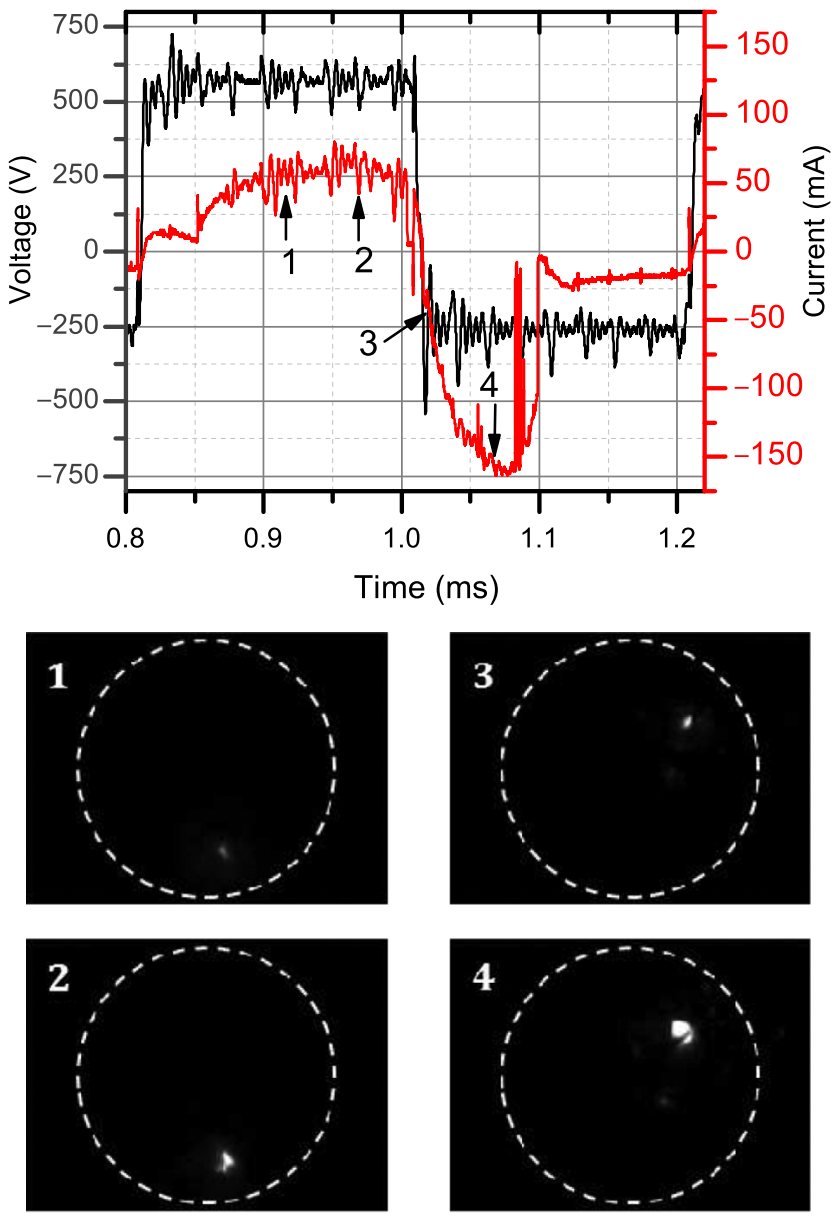

$500 \mu \mathrm{m}$

FIG. 2. Current and voltage time evolutions at $2500 \mathrm{~Hz}$ and corresponding frames showing the presence of discharge events. In the dashed line, circles show the approximate location of the sample boundary. medium under a given electric field $E$ is defined by the following expression:

$$
v_{c}=\mu_{C} E,
$$

where $\mu_{C}$ is the mobility (in $\mathrm{m}^{2} \mathrm{~s}^{-1} \mathrm{~V}^{-1}$ ) of charge carriers. The mobility of common charge carriers in water is given in Table I. From Fig. 2, we can estimate the anodic voltage to be about $600 \mathrm{~V}$ and the cathodic one around $-250 \mathrm{~V}$. The distance between the counterelectrodes and the sample being about $20 \mathrm{~cm}$, the anodic and cathodic electric fields $E a$ and $E c$ are equal to 3 and $1.25 \mathrm{k} \mathrm{V} \mathrm{m}^{-1}$, respectively. Hence, velocities of different species under anodic and cathodic electric fields can be easily calculated as well as the distance traveled within a half-period of time-200 $\mu \mathrm{s}$ at $2.5 \mathrm{kHz}$ (see Table I). Then, it appears that, depending on the charge carrier, the distance varies from 31 to $217 \mathrm{~nm}$ from the substrate surface.

These distances must be compared with the thickness $\lambda_{D}$ of an EDL, which can be estimated by the Debye-Hückel relation

$$
\lambda_{D}=\left(\frac{\varepsilon_{0} \varepsilon_{r w} N_{A} k_{B} T}{2 F^{2} I}\right)^{1 / 2}
$$

where $\varepsilon_{0}$ and $\varepsilon_{r w}$ are the permittivity in vacuum and the dielectric constant of water (81), respectively, $N_{A}$ is Avogadro's number, $F$ is Faraday's constant, $k_{B}$ is the Boltzmann's constant, $T$ is the electrolyte temperature, and $I$ is the ionic strength of the electrolyte. The ionic strength is

$$
I=\frac{1}{2} \sum_{i=1}^{n} c_{i} z_{i}^{2}
$$

where $c_{i}$ and $z_{i}$ are, respectively, the concentration and the valence of ion $i$. For a conventional PEO electrolyte $\left([\mathrm{KOH}]=0.018 \mathrm{~mol} \mathrm{~L}^{-1}, \quad\left[\mathrm{Na}_{2} \mathrm{SiO}_{3}\right]=0.0135 \mathrm{~mol} \mathrm{~L}^{-1}\right)$, $I$ equals $0.0585 M$. Then, $\lambda_{D}$ can be estimated to be about $40 \mathrm{~nm}$. This means that at this frequency, the duration of a half-period is not sufficient to completely expel oppositely charged species (and repeal equally charged species). In other terms, the short duration of the pulses makes the buildup of the EDL impossible. Consequently, the externally applied electric field is not shielded anymore by the EDL under cathodic polarization, making breakdown possible under this polarization.

Figure 3 shows the distance traveled by $\mathrm{Na}^{+}$and $\mathrm{K}^{+}$ anions as a function of time under the anodic electric field. It appears that the time needed to travel a distance corresponding to the EDL thickness is between 175 and $260 \mu$ s. In other terms, cathodic MDs should appear at a frequency higher than a threshold within the range [1.92-2.86 kHz]. Figure 1 shows that cathodic MDs appear at a frequency higher than $2 \mathrm{kHz}$, a value in good agreement with theoretical results. Since cathodic discharges are associated with an increase in the cathodic current, it is 
TABLE I. Ionic mobilities of different possible charge carriers and their velocity $v_{\text {anodic }}$ and $v_{\text {cathodic }}$ under anodic and cathodic polarization, respectively. Distance $d_{\text {anodic }}$ and $d_{\text {cathodic }}$ traveled under anodic and cathodic polarization, respectively, at $2500 \mathrm{~Hz}$ (i.e., 200- $\mu$ s half-period). Data for ion mobility are taken from Ref. [33].

\begin{tabular}{lccccc}
\hline \hline Carrier & Mobility in $\mathrm{H}_{2} \mathrm{O}\left(\mathrm{m}^{2} \mathrm{~s}^{-1} \mathrm{~V}^{-1}\right)$ & $v_{\text {anodic }}\left(\mathrm{m} \mathrm{s}^{-1}\right)$ & $v_{\text {cathodic }}\left(\mathrm{m} \mathrm{s}^{-1}\right)$ & $d_{\text {anodic }}(\mathrm{nm})$ at $2500 \mathrm{~Hz}$ & $d_{\text {cathodic }}(\mathrm{nm})$ at $2500 \mathrm{~Hz}$ \\
\hline $\mathrm{K}^{+}$ & 7.62 & $2.310^{-4}$ & $9.510^{-5}$ & 46 & 19 \\
$\mathrm{Na}^{+}$ & 5.19 & $1.610^{-4}$ & $6.510^{-5}$ & 31 & 13 \\
$\mathrm{H}^{+}$ & 36.23 & $1.110^{-3}$ & $4.510^{-4}$ & 217 & 90 \\
$\mathrm{OH}^{-}$ & 20.64 & $6.210^{-4}$ & $2.610^{-4}$ & 124 & 52 \\
\hline \hline
\end{tabular}

interesting to note that Parfenov et al. [7] and Yerokhin et al. [34] have observed a significant increase in cathodic current starting in the $\mathrm{kHz}$ range when they swept the frequency in a range between $20 \mathrm{~Hz}$ and $20 \mathrm{kHz}$ (see Fig. 4 in Ref. [7] and Fig. 1 in Ref. [34]). These results, although obtained in experimental conditions that are slightly different from those studied here, strengthen the consistency of the present results.

These findings raise the question of the role of this particular type of cathodic MDs. In uncommon electrolytes (e.g., $\mathrm{NH}_{4} \mathrm{~F}$ based), cathodic discharges tend to delaminate the coating. Therefore, they are considered as detrimental to the coating growth. On the other hand, in the present conditions, no delamination nor any other obvious detrimental effect (see Fig. 6 of Ref. [31]) had been observed. Power consumptions at $1.5 \mathrm{kHz}$ (without cathodic MDs) and the one at $2.5 \mathrm{kHz}$ (with cathodic MDs) are rather similar (around $50 \mathrm{~W}$ on the small sample area). However, the presence of cathodic discharges may be a more efficient way to transfer energy to the coating either by increasing the growth rate or by promoting high temperature phases such as $\alpha-\mathrm{Al}_{2} \mathrm{O}_{3}$. A specific study is necessary to state on the effect of high-frequency-induced cathodic MDs on coating growth and crystallographic composition.

In any case, these results show that the mobility of charges in the electrolyte is an important parameter of the PEO process as well as the intensities of electric fields

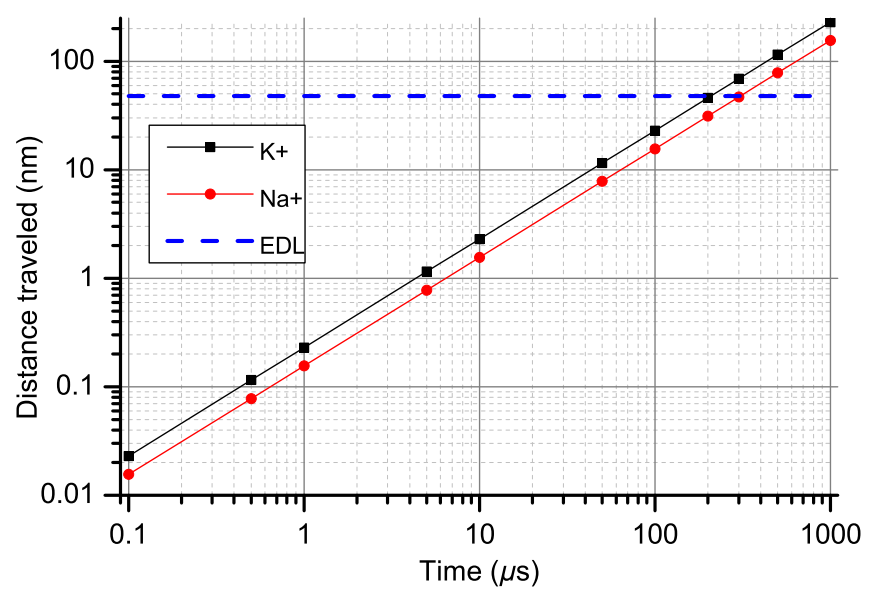

FIG. 3. Distance traveled by different charge carriers under anodic polarizations versus time. The EDL thickness is showed by the dotted line. (anodic and cathodic). It must be taken into account both in the elaboration of electrolytes (as $p \mathrm{H}$ or conductivity are) and in the design of reactors. Indeed, if high-frequencyinduced cathodic discharges are of interest to improve coating growth or heating (i.e., the promotion of hightemperature phases), then it might be useful to decrease the threshold frequency by using less mobile ionic species (or slightly decrease $E c$ ). Otherwise, if these cathodic MDs do not show any assets for coating growth, then it would be desirable to extend the frequency range over which they do not appear. To do so, very mobile species or higher $E c$ are needed to make the EDL shielding build up very rapidly.

\section{ACKNOWLEDGMENTS}

We greatly acknowledge Professor T. W. Clyne and Sam Troughton for using the PEO equipment and for discussions. The authors also acknowledge Dr. Rudy Romain for assistance in the manuscript elaboration as well as Dr. P. Lukeš and Dr. I. V. Bardin for fruitful exchanges. This work has been made as part of the COST TD1208 network and has received support through a "Short Term Scientific Mission" program. This work was also supported by the French Government through the program "Investissements d'avenir" operated by the French National Research Agency (ANR) and referenced to as ANR-11LABX-0008-01 (LabEx DAMAS). A. N. acknowledges Fundacion Banco Santander for financial support through Santander Mobility Scholarship.

[1] E. Matykina, R. Arrabal, P. Skeldon, and G. E. Thompson, Optimisation of the plasma electrolytic oxidation process efficiency on aluminium, Surf. Interface Anal. 42, 221 (2010).

[2] E. Matykina, R. Arrabal, P. Skeldon, and G. E. Thompson, Investigation of the growth processes of coatings formed by AC plasma electrolytic oxidation of aluminium, Electrochim. Acta 54, 6767 (2009).

[3] R. Arrabal, E. Matykina, F. Viejo, P. Skeldon, G. E. Thompson, and M.C. Merino, AC plasma electrolytic oxidation of magnesium with zirconia nanoparticles, Appl. Surf. Sci. 254, 6937 (2008).

[4] M. P. Kamil, M. Kaseem, and Y. G. Ko, Soft plasma electrolysis with complex ions for optimizing electrochemical performance, Sci. Rep. 7, 44458 (2017). 
[5] A. L. Yerokhin, A. Shatrov, V. Samsonov, P. Shashkov, A. Pilkington, A. Leyland, and A. Matthews, Oxide ceramic coatings on aluminium alloys produced by a pulsed bipolar plasma electrolytic oxidation process, Surf. Coat. Technol. 199, 150 (2005).

[6] F. Jaspard-Mécuson, T. Czerwiec, G. Henrion, T. Belmonte, L. Dujardin, A. Viola, and J. Beauvir, Tailored aluminium oxide layers by bipolar current adjustment in the plasma electrolytic oxidation (PEO) process, Surf. Coat. Technol. 201, 8677 (2007).

[7] E. V. Parfenov, A. L. Yerokhin, and A. Matthews, Frequency response studies for the plasma electrolytic oxidation process, Surf. Coat. Technol. 201, 8661 (2007).

[8] E. V. Parfenov, A. Yerokhin, R. R. Nevyantseva, M. V. Gorbatkov, C. J. Liang, and A. Matthews, Towards smart electrolytic plasma technologies: An overview of methodological approaches to process modelling, Surf. Coat. Technol. 269, 2 (2015).

[9] A. L. Yerokhin, X. Nie, A. Leyland, A. Matthews, and S. J. Dowey, Plasma electrolysis for surface engineering, Surf. Coat. Technol. 122, 73 (1999).

[10] C. S. Dunleavy, I. O. Golosnoy, J. A. Curran, and T. W. Clyne, Characterisation of discharge events during plasma electrolytic oxidation, Surf. Coat. Technol. 203, 3410 (2009).

[11] R. Arrabal, E. Matykina, T. Hashimoto, P. Skeldon, and G. E. Thompson, Characterization of AC PEO coatings on magnesium alloys, Surf. Coat. Technol. 203, 2207 (2009).

[12] H. Habazaki, S. Tsunekawa, E. Tsuji, and T. Nakayama, Formation and characterization of wear-resistant PEO coatings formed on $\beta$-titanium alloy at different electrolyte temperatures, Appl. Surf. Sci. 259, 711 (2012).

[13] J. Martin, A. Melhem, I. Shchedrina, T. Duchanoy, A. Nominé, G. Henrion., T. Czerwiec, and T. Belmonte, Effects of electrical parameters on plasma electrolytic oxidation of aluminium, Surf. Coat. Technol. 221, 70 (2013).

[14] A. Melhem, G. Henrion., T. Czerwiec, J. L. Briançon, T. Duchanoy, F. Brochard, and T. Belmonte, Changes induced by process parameters in oxide layers grown by the PEO process on Al alloys, Surf. Coat. Technol. 205, S133 (2011).

[15] E. Matykina, A. Berkani, P. Skeldon, and G. E. Thompson, Real-time imaging of coating growth during plasma electrolytic oxidation of titanium, Electrochim. Acta 53, 1987 (2007).

[16] L. Yerokhin, L. O. Snizhko, N. L. Gurevina, A. Leyland, A. Pilkington, and A. Matthews, Discharge characterization in plasma electrolytic oxidation of aluminium, J. Phys. D 36, 2110 (2003).

[17] S. Stojadinovic, J. Jovovic, M. Petkovic, R. Vasilic, and N. Konjevic, Spectroscopic and real-time imaging investigation of tantalum plasma electrolytic oxidation (PEO), Surf. Coat. Technol. 205, 5406 (2011).

[18] S. Stojadinovic, R. Vasilic, M. Petkovic, and L. Zekovic, Plasma electrolytic oxidation of titanium in heteropolytungstate acids, Surf. Coat. Technol. 206, 575 (2011).

[19] S. Dunleavy, J. A. Curran, and T. W. Clyne, Time dependent statistics of plasma discharge parameters during bulk AC plasma electrolytic oxidation of aluminium, Appl. Surf. Sci. 268, 397 (2013).

[20] A. Nominé, J. Martin, C. Noël, G. Henrion, T. Belmonte, I. V. Bardin, V. L. Kovalev, and A. G. Rakoch, The evidence of cathodic micro-discharges during plasma electrolytic oxidation process, Appl. Phys. Lett. 104, 081603 (2014).

[21] A. G. Rakoch, A. A. Gladkova, Z. Linn, and D. M. Strekalina, The evidence of cathodic micro-discharges during plasma electrolytic oxidation of light metallic alloys and micro-discharge intensity depending on $\mathrm{pH}$ of the electrolyte, Surf. Coat. Technol. 269, 138 (2015).

[22] A. Nomine, J. Martin, G. Henrion, and T. Belmonte, Effect of cathodic micro-discharges on oxide growth during plasma electrolytic oxidation (PEO), Surf. Coat. Technol. 269, 131 (2015).

[23] A. Nominé, J. Martin, C. Noël, G. Henrion, T. Belmonte, I. V. Bardin, and P. Lukeś, Surface charge at the oxide/ electrolyte interface: Toward optimization of electrolyte composition for treatment of aluminum and magnesium by plasma electrolytic oxidation, Langmuir 32, 1405 (2016).

[24] S. P. Sah, E. Tsuji, Y. Aoki, and H. Habazaki, Cathodic pulse breakdown of anodic films on aluminium in alkaline silicate electrolyte-Understanding the role of cathodic half-cycle, Corros. Sci. 55, 90 (2012).

[25] P. Lukeš, M. Clupek, V. Babicky, and P. Sunka, The role of surface chemistry at ceramic/electrolyte interfaces in the generation of pulsed corona discharges in water using porous ceramic-coated rod electrodes, Plasma Process. Polym. 6, 719 (2009).

[26] S. C. Troughton, A. Nomine, A. V. Nomine, G. Henrion, and T. W. Clyne, Synchronised electrical monitoring and high speed video of bubble growth associated with individual discharges during plasma electrolytic oxidation, Appl. Surf. Sci. 359, 405 (2015).

[27] J. Jovovic, S. Stojadinovic, N. M. Sisovic, and N. Konjevic, Spectroscopic study of plasma during electrolytic oxidation of magnesium- and aluminium-alloy, J. Quant. Spectrosc. Radiat. Transfer 113, 1928 (2012).

[28] J. Jovovic, S. Stojadinovic, N. M. Sisovic, and N. Konjevic, Spectroscopic characterization of plasma during electrolytic oxidation (PEO) of aluminium, Surf. Coat. Technol. 206, 24 (2011).

[29] S. Stojadinovic, R. Vasilic, J. Radic-Peric, and M. Peric, Characterization of plasma electrolytic oxidation of magnesium alloy AZ31 in alkaline solution containing fluoride, Surf. Coat. Technol. 273, 1 (2015).

[30] C. S. Dunleavy, J. A. Curran, and T. W. Clyne, Self-similar scaling of discharge events through PEO coatings on aluminium, Surf. Coat. Technol. 206, 1051 (2011).

[31] S. C. Troughton, A. Nominé, J. Dean, and T. W. Clyne, Effect of individual discharge cascades on the microstructure of plasma electrolytic oxidation coatings, Appl. Surf. Sci. 389, 260 (2016).

[32] A. Nomine, S. C. Troughton, A. V. Nomine, G. Henrion, and T. W. Clyne, High speed video evidence for localised discharge cascades during plasma electrolytic oxidation, Surf. Coat. Technol. 269, 125 (2015).

[33] P. Atkins and J. de Paula, Atkins' Physical Chemistry (Oxford University Press, Oxford, 2010).

[34] A. Yerokhin, E. V. Parfenov, and A. Matthews, In situ impedance spectroscopy of the plasma electrolytic oxidation process for deposition of Ca- and P-containing coatings on Ti, Surf. Coat. Technol. 301, 54 (2016). 